\title{
Clinical study of a typical pityriasis rosea in patients attending the department of dermatology and venereology at Rizgary Teaching Hospital in Erbil city
}

Received: $19 / 6 / 2010$

Accepted: 9/10/2010

Intiha M. Ridha*

Abstract

Background and objectives: The aim of this study was to measure the rate of a typical cases of pityriasis rosea among dermatological visit and to outline the various clinical presentations of a typical pityriasis rosea disease.

Methods: This descriptive study was conducted for a period extended from October 2007 through June 2008. 88 patients who diagnosed to have pityriasis rosea were enrolled in this study. The diagnosis was based on history and clinical examination; questionnaire was designed to provide relative data and all patients' data were recorded at time of diagnosis. Investigations in certain cases were done to aid in the diagnosis.

Results: A typical pityriasis rosea was found in $38.5 \%$ patients. Absence of herald patch in $17 \%$ of patients, papular rosea in $8 \%$, inverse pityriasis rosea in $6.8 \%$, localized pityriasis rosea in $4.5 \%$, unilateral/inverse in $1.1 \%$ and urticarial in $1.1 \%$ of patients

Conclusion: A typical pityriasis rosea is not uncommon and different forms of a typical pityriasis rosea exist. Investigations are sometimes needed to confirm the diagnosis.

Key words: A typical pityriasis rosea, herald patch, inverse pityriasis rosea.

\section{Introduction}

Pityriasis rosea (PR) is an acute, selflimited eruption commonly observed in otherwise healthy children and young adults; although it may develop at any age ${ }^{1}$. Pityriasis rosea has been considered to be viral exanthem. Its clinical presentation supports this concept. The disease typically begins with a solitary macule that heralds the eruption called the herald patch ${ }^{2}$. Atypical PR occurs in $20 \%$ of patients. The incidence of the herald patch varies to a great extent, from $40-76 \%{ }^{3}$. The primary plaque may be double or multiple lesions often close together. Pityriasis rosea may be atypical in distribution of lesions. Localized PR of few lesions, often in the groin or axilla, may be seen ${ }^{4}$. Unilateral PR that doesn't cross midline has been reported ${ }^{5,6}$. Inverse PR which spare trunk and seen in face, axilla, inguinal, arm, and leg areas ${ }^{7}$. Pityriasis rosea could be recurrent in about $2 \%$ of $^{\text {cases }^{8}}{ }^{8}$.The diagnosis of $P R$ is based on careful history taking and physical exam. Differential diagnoses include drug eruption, secondary syphilis, tinea corporis, guttate psoriasis, pityriasis lichenoid chronica, seborrhoeic dermatitis, lichen planus ${ }^{1}$. The most important part of treating patients with $P R$ is reassurance that the rash will resolve, this can be helped by using topical steroids, oral antihistamines, topical menthol-phenol lotions and oatmeal baths ${ }^{2}$. Other drugs that can be used in the treatment of PR are erythromycin and acyclovir ${ }^{9}$.

* Department of dermatology, College of Medicine, HMU, Erbil, Iraq 


\section{Methods}

This descriptive study was conducted for a period extended from October 2007 through June 2008. Eighty eight patients who diagnosed to have pityriasis rosea were enrolled in this study. The diagnosis of pityriasis rosea was based on clinical characteristic of PR. All patients were interviewed by researcher for detailed history concerned with the following points: Age and gender, duration of the disease at time of visit, pruritus, fever, malaise, arthralgia, headache, family history , history of prodromal symptoms before eruptions, presence of herald patch and the interval time for secondary eruptions, recent history of any drug intake, history of genital and extra genital lesions was obtained from any adolescents and adults patients with classical PR but lack herald patch for seeking for primary syphilis. History of contact with animals (sheep, goat, cat and dog) has been obtained in those patients with localized form of PR. Complete clinical examination was carried out by researcher. A typical pityriasis rosea in this study was classified according to the absence of herald patch, atypical morphology and a typical distribution of lesions $s^{3,4,5,7-12}$. Two cases with oral lesions have been followed by researcher at 2 weeks interval till their skin lesion appeared in order to confirm the association of their oral lesions with the disease. -VDRL done for all adolescents and adults (10cases) with classical distribution and morphology of lesions that lacks herald patch and for one female with palm involvement.

-Skin scraping for fungus: done in localized cases with lack of herald patch

-Skin biopsy was done for inverse PR (face \& arms), inverse unilateral, localized $\mathrm{PR}$, and 2 cases of PR lasted more than 3 months. Data were analysed using the Statistical Package for Social Science (SPSS, Version 16.0)

\section{Results}

Classical pityriasis rosea was the commonest morphological type and found in 54 $(61.5 \%)$ patients, 32 of them were females and 22 were males. A typical pityriasis rosea was found in $38.5 \%$ of patients, 16 of them were females and 18 were males. Cases with absence of herald patch were considered atypical, but with classical distribution and morphology of secondary lesions, it was found in $15(17 \%)$ patients. Table (1) shows the different locations of the herald patch. Other a typical cases include: papular rosea in $7(8 \%)$ patients, inverse PR in $6(6.8 \%)$ patients, localized pityriasis rosea in $4(4.5 \%)$ patients, unilateral/inverse in $1(1.1 \%)$ patient and urticarial in $1(1.1 \%)$ patient (Table 1$)$. In papular rosea 2 patients were children, 2 were adolescents and 3 were young adults, only one patient was female. In inverse rosea, 2 patients had involvement of both lower and upper limbs, 3 had only lower limbs involvement and 1 had involvement of face and upper limbs. Four patients were males and 2 were females. One female had unilateral/ inverse rosea affecting right thigh and leg. In localized PR, 3 patients were females and 1 was male. Two cases had few localized lesions in the neck and adjacent parts of chest. Figure (1) shows the distribution of the secondary lesions. One case shows lesions in the left flank, other show lesions in the lower part of the abdomen and buttock. Scraping for fungus was negative in all patients. One female presented with persistent severely pruritic annular urticarial scaly plaques on trunk, arms and thighs following a primary patch in the right arm for unknown period. She was designated to have urticarial PR depending on clinical presentation. 
Table 1: Herald patch distribution

Herald patch

\begin{tabular}{lc}
\hline Site & Percent \\
Trunk & 50.8 \\
Thighs & 12.7 \\
Neck & 11.1 \\
Arms & 7.9 \\
Legs & 6.3 \\
Forearm & 4.8 \\
Shoulders & 3.2 \\
Ankls & 1.6 \\
Buttoks & 1.6 \\
Total & 100
\end{tabular}

Table 2: Different clinical presentations of PR

\begin{tabular}{|c|c|c|c|c|c|}
\hline \multirow{2}{*}{\multicolumn{2}{|c|}{ Presentation }} & \multicolumn{2}{|c|}{ Herald patch } & \multirow{2}{*}{ Frequency } & \multirow{2}{*}{ Percent } \\
\hline & & \multirow{2}{*}{$\begin{array}{c}\text { yes } \\
54\end{array}$} & \multirow{2}{*}{$\begin{array}{c}\text { no } \\
0\end{array}$} & & \\
\hline 1-Classical & & & & 54 & 61.5 \\
\hline 2-Non-class & cal & & & & \\
\hline Morphology & Distribution & & & & \\
\hline Classical & Classical & 0 & 15 & 15 & 17 \\
\hline Papular & Classical & 1 & 6 & 7 & 8 \\
\hline Classical & Inverse & 5 & 1 & 6 & 6.8 \\
\hline Classical & Localized & 2 & 2 & 4 & 4.5 \\
\hline Classical & $\begin{array}{l}\text { Unilateral/ } \\
\text { inverse }\end{array}$ & 0 & 1 & 1 & 1.1 \\
\hline Urticarial & Classical & 1 & 0 & 1 & 1.1 \\
\hline Total & & 63 & 25 & 88 & 100 \\
\hline
\end{tabular}




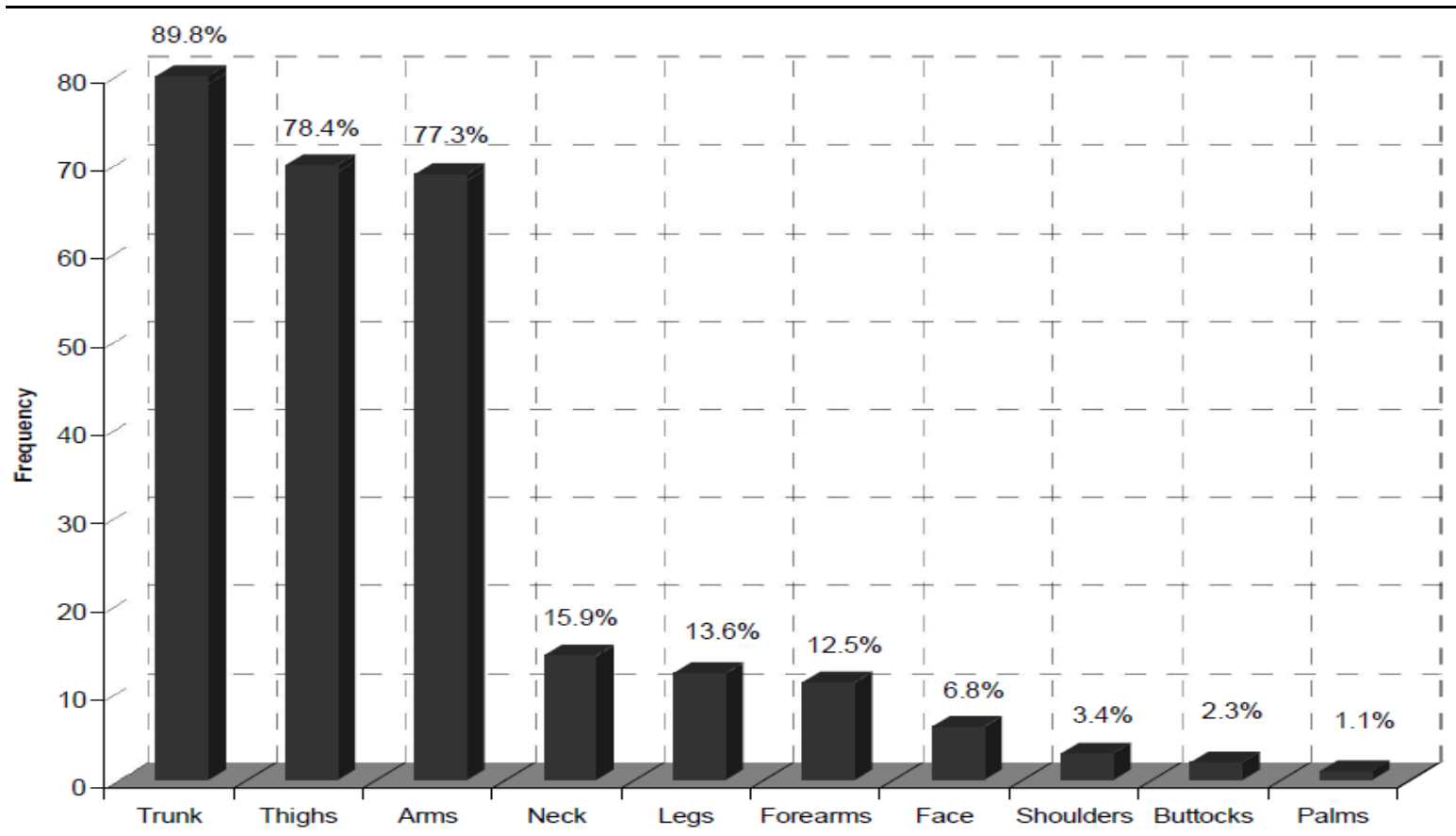

Figure 1: Distribution of secondary eruptions. Patient usually have combined involvement

\section{Discussion}

In our daily practice at Rizgary teaching hospital in dermatology department, we have noticed that there are different forms of a typical pityriasis rosea and some times the diagnosis is difficult. In this study $61.5 \%$ of the cases presented with typical pityriasis rosea, which correspond to other study ${ }^{10}$ which reported typical PR in $62 \%$ of cases and a typical in 38\% cases. This study reported herald patch in 63 (71.6\%) patients, with the most common site being the trunk $50.8 \%$, this result is close to the finding of other studies ${ }^{10,11}$, they reported herald patch in $66.6 \%$ and $70 \%$, with most common site being the trunk $48.7 \%$ and $57.14 \%$ respectively. The secondary lesions most commonly involved the trunk $89.8 \%$, thighs $78.4 \%$, arms $77.3 \%$ and less commonly neck, legs, forearms and face. These results corroborate data in earlier studies ${ }^{10,11}$. Papular PR was equally presented in children, adolescent and young adults, in another study papular PR occurs especially in blacks, children and pregnant women ${ }^{12}$. Inverse PR was found in $6.8 \%$ of patients; this is close to other study 13 , which they reported inverse PR in $6 \%$ of cases. Localized PR was present in $4 \%$ in other study ${ }^{10}$; this study also reported localized PR in $4.5 \%$ of cases. There are few reports about palmoplantar involvement in PR ${ }^{14}$, this study report 1 case when there was involvement of palm in addition to classical presentations. Involvement of the oral mucous membrane is uncommon; however, its incidence varies in different studies from $1 \%{ }^{15}$ to approximately $16 \%$ 16 . In this study oral lesions were reported in $2.3 \%$ of patients.

\section{References}

1. Gonzalez LM, Allen RA, Janniger CK, Schwartz RA. Pityriasis rosea: An important papulosequamous disorder. Int J Dermatol 2005; 44: -64.

2. Allen RA, Schwartz RA. Pityriasis Rosea. eMedicine 2007 [online]. Available from: http:// www.emedicine.com/derm/topic335.htm. [Accessed on 15/7/2008].

3. Chuh AA, Lee A, Zawar V, Sciallis G, Kempf W . Pityriasis rosea - An update. Indian J Dermatol Venereol Lepro 2005a; 71: 311-5.

4. Ahmed I, Charles-Holmes R. Localized pityriasis rosea. Clin Exp Dermatol 2000 Nov; 25(8): 624-6. 
5. Del Campo DB, Barsky S, Tisocco L. Pityriasis rosea unilateralis. Int J Dermatol 1983; 5: 312-3.

6. Brar BK, Pall A, Gupta RR. Pityriasis rosea unilateralis. Indian J Dermatol Venereol Leprol 2003; 69: 42-3.

7. Gibney M D, Leonardi C L. Acute papulosquamous eruption of the extremities demonstrating an isomorphic response. Inverse pityriasis rosea (PR). Arch Dermatol 1997; 133: 651-4.

8. Singh SK, Singh S, Pandey SS. Recurrent pityriasis rosea. Indian J Dermatol Venereol Leprol 1998; 64: 237.

9. Sharma PK, Yadav TP, Gautam RK, Taneja N, Satyanarayana L. Erythromycin in pityriasis rosea: A double-blind, placebo controlled clinical trial. J Am Acad Dermatol 2000; 42: 241-4.

10. Egwin AS, Martis J, Bhat RM, Kamath $\mathrm{GH}$, Nanda KB. A clinical study on pityriasis rosea. Indian J Dermatol 2005; 50: 136-8.

11. Ahmed MA. Pityriasis rosea in the Sudan. Int J Dermatol 1986; 25: 184- 5.

12. Bernardin RM. Ritter SE. Murchland MR. Papular pityriasis rosea. Cutis 2002; 70: 51-5.

13. Tay YK, Goh CL. One-year review of pityriasis rosea at the National Skin Centre, Singapore. Ann Acad Med Singapore 1999; 28: 829- 31.

14. Deng $\mathrm{Y}$, Li H, Chen X. Palmoplantar pityriasis rosea: two case reports. J Eur Acad Dermatol Venereol 2007; 21: 406-7.

15. Dashore A, Jain VK, Chaudhry SD. Oral lesions in pityriasis rosea. Indian J Dermatol Venereol Leprol 1988; 54: 140-1.

16. Vidimos AT, Camisa C. Tongue and cheek: oral lesions in pityriasis rosea. Cutis 1992; 50: 276-80. 